\title{
IL-17 in Systemic Lupus Erythematosus
}

\author{
José C. Crispín and George C. Tsokos \\ Department of Medicine, Beth Israel Deaconess Medical Center, Harvard Medical School, Boston, MA 02130, USA \\ Correspondence should be addressed to George C. Tsokos, gtsokos@bidmc.harvard.edu
}

Received 5 February 2010; Accepted 7 February 2010

Academic Editor: Brian Poole

Copyright ( 2010 J. C. Crispín and G. C. Tsokos. This is an open access article distributed under the Creative Commons Attribution License, which permits unrestricted use, distribution, and reproduction in any medium, provided the original work is properly cited.

IL-17 is a cytokine with powerful proinflammatory activity. Production of IL-17 is abnormally increased in patients with systemic lupus erythematosus (SLE), a multiorgan chronic autoimmune disease. In patients with SLE, CD3 ${ }^{+} \mathrm{CD} 4^{-} \mathrm{CD} 8^{-}$(double negative) $\mathrm{T}$ cells are an important source of IL-17. IL-17 produced by double negative and CD4 T cells participates in the pathogenesis of the disease. IL-17-producing T cells are present in the kidneys of patients with lupus nephritis. IL-17 increased production in patients with SLE can amplify the immune response by increasing target organ inflammation and damage and by augmenting the production of antibodies by B cells.

\section{Introduction}

Systemic lupus erythematosus (SLE) is an autoimmune disorder that appears in genetically prone individuals triggered by ill-defined environmental factors [1]. Patients with SLE develop an immune response against numerous, mostly intracellular self-antigens. This chronic response alters the function of the immune system and releases self-antigens that along with autoantibodies form immune complexes that deposit in susceptible vascular beds, mostly in skin, joints, and renal glomeruli. Immune complex deposition causes local inflammation and tissue damage that probably amplify the autoimmune response creating thus a vicious cycle.

Cytokines are intimately involved in SLE pathogenesis. They contribute to the underlying immune dysfunction and to immune-mediated events that damage target organs. IL17 is a cytokine with powerful inflammatory properties. Recent evidence suggests that it is involved in the pathogenesis of SLE. In this paper, we discuss the evidence that links IL-17 to SLE in both human and animal models. Data indicates that IL-17-driven inflammation amplifies SLE-induced tissue damage and contributes to tolerance breakdown in SLE patients.

\section{Interleukin-17}

Interleukin (IL)-17 is an ancient cytokine intimately related with epithelia-particularly with the intestinal mucosa $[2,3]$. Its main receptor, IL-17RA, is broadly expressed on epithelial and endothelial cells as well as on immune cells [4-6]. It is produced by several cell types including activated $\mathrm{T}$ cell subsets $\left(\mathrm{CD}^{+}, \mathrm{CD}^{+}\right.$, and TCR- $\alpha \beta \mathrm{CD} 4^{-} \mathrm{CD} 8^{-}$, TCR$\gamma \delta)$, natural killer cells, and neutrophils [7]. IL-17 plays an essential role in the immune response against bacteria and fungi [8].

IL-17 has pro-inflammatory capacities exerted through its ability to induce secretion of chemokines such as IL-8, monocyte chemoattractant protein-1 (MCP-1), and growthrelated oncogene protein- $\alpha$, which recruit monocytes and neutrophils [9-12]. IL-17 also facilitates $\mathrm{T}$ cell activation and infiltration into tissues by upregulating the expression of intercellular adhesion molecule-1 (ICAM-1) and amplifies the immune response by inducing the production of IL-6, prostaglandin $\mathrm{E}_{2}$, granulocyte-macrophage colony stimulating factor (GM-CSF), and granulocyte colony stimulating factor [13-15]. Additionally, IL-17 acts synergistically with other cytokines, particularly IL- $1 \beta$, tumor necrosis factor (TNF) $-\alpha$, and interferon (IFN) $-\gamma[13,16]$. 


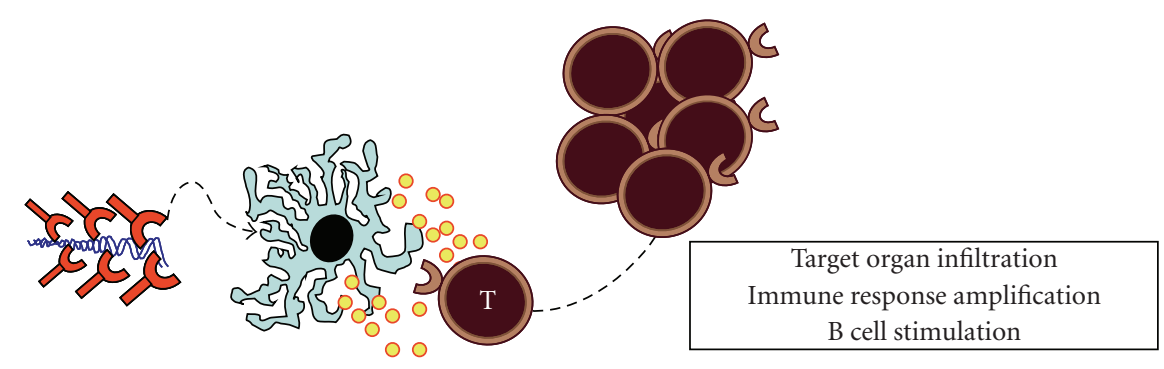

FIgure 1: The IL-17 response is amplified in SLE. Nucleic acid-containing immune complexes and other inflammatory stimuli (e.g., cytokines) induce the production of pro-inflammatory cytokines by dendritic cells. These factors, along with others not yet identified, favor the generation of pro-inflammatory IL-17-producing $\mathrm{T}$ cell subsets (i.e., $\mathrm{T}_{\mathrm{H}} 17$ and $\mathrm{DN} \mathrm{T}$ cells) able to migrate to target organs and inflict damage. Produced IL-17 amplifies the inflammatory response and stimulates other cell types (e.g., B cells).

IL-17-producing cells have been recently implicated in the pathogenesis of a wide range of inflammatory and autoimmune diseases including psoriasis, rheumatoid arthritis (RA) [17, 18], inflammatory bowel disease (IBD) [19], systemic sclerosis [20], and systemic lupus erythematosus (SLE) $[21,22]$.

\section{IL-17 Production in SLE}

Evidence indicates that production of IL-17 is abnormally high in patients with SLE. Its levels are increased in SLE sera [23] and correlate with SLE disease activity $[22,24]$. Moreover, the frequency of IL-17-producing T cells is increased in the peripheral blood of patients with SLE [21, $22,25]$.

A significant fraction of the IL-17 produced in SLE patients derives from double negative (DN) TCR$\alpha \beta^{+} \mathrm{CD} 4^{-} \mathrm{CD} 8^{-} \mathrm{T}$ cells [21]. DN T cells represent a small T cell subset in healthy individuals. These cells are expanded in peripheral blood of SLE patients and produce proinflammatory chemokines and cytokines including IL-17, IFN- $\gamma$, and IL- $1 \beta$ [26]. Support for their pathogenic role derives from the fact that IL-17-producing T cells have been observed in kidneys of patients with lupus nephritis [21,27], among infiltrates rich in DN T cells [21].

Apart from its direct pro-inflammatory activity, the effects of IL-17 in other cell types may contribute to SLE pathogenesis. Increased production of total IgG, anti-dsDNA IgG, and IL- 6 by peripheral blood mononuclear cells of patients with lupus nephritis was observed when they were cultured in the presence of IL-17 [28]. These findings suggest that IL-17 may participate in the activation of B cells in patients with SLE.

IL-17 production is also high in mice affected by lupuslike diseases [29]. An abnormally high fraction of T cells from MRL/lpr mice produce IL-17 [29]. In these mice, as in patients with SLE, DN T cells are an important source of IL-17. Interestingly, lymph node cells derived from MRL/lpr mice were able to cause glomerulonephritis when transferred into lymphocyte-deficient $\mathrm{Rag}^{-/-}$mice. The effect depended on their prestimulation with IL-23, a cytokine known to stimulate IL-17 production in humans and mice [29]. IL-17, along with IL-13 and IFN- $\gamma$, is the main cytokine produced by infiltrating $\mathrm{T}$ cells in nephritic kidneys of MRL/lpr mice $[29,30]$.

In SNF1 mice (New Zealand Black x SWR F1), spleen cells produce significantly higher amounts of IL-17 than spleen cells from control mice when cultured in the presence of nucleosomes, a known lupus autoantigen [31]. In these mice as in the MRL/lpr, IL-17-producing T cells are detected in kidneys affected by nephritis. Interestingly, clinical disease improved along with decreased IL-17 production in mice treated with a tolerating regime induced with a histonederived peptide [31], or with nasal administration of antiCD3 [32].

The BXD2 mouse, a model that spontaneously develops arthritis, glomerulonephritis, and autoantibodies [33], has high IL-17 levels in serum as well as increased numbers of IL$17^{+}$cells in the spleen [34]. Accordingly, upon stimulation an increased fraction of BXD2 T cells produce IL-17. Humoral responses are strongly augmented in these mice [35]. They spontaneously develop germinal centers (GC) in the spleen where IL- $17^{+} \mathrm{T}$ cells colocalize with IL- $17 \mathrm{R}^{+} \mathrm{B}$ cells [34]. The importance of IL-17 in this process was demonstrated when B6 and predisease BXD2 mice were infected with an IL-17coding adenovirus that increased IL-17 levels and induced the formation of germinal centers in both mouse strains. Concordantly, formation of GC diminished and production of anti-DNA and anti-histone antibodies was abrogated in BXD2 IL-17R deficient mice [34]. This supports the concept that IL-17 can provide help to B cells.

\section{Amplification of the IL-17 Response in SLE}

IL-17 is the prototypical cytokine of a CD4 T cell effector subset known as $\mathrm{T}_{\mathrm{H}} 17$ cells [7]. $\mathrm{T}_{\mathrm{H}} 17$ cells are generated when naïve CD4 $\mathrm{T}$ cells are primed in the presence of TGF- $\beta$ and certain inflammatory cytokines (i.e., IL-21, IL6, and IL-23) [36-38]. Patients with SLE have a higher frequency of IL-17-producing $\mathrm{T}$ cells $[21,22,25]$. It is thus assumed that the generation of $\mathrm{T}_{\mathrm{H}} 17$ cells is favored in SLE patients. Nevertheless, this has not been directly addressed in any study. Moreover, cells different than CD4 $\mathrm{T}$ cells are important sources of IL-17 and particularly in SLE, DN T cells are important producers of this cytokine [21]. 
From a theoretical point of view, the SLE environment is ideal for the generation of $\mathrm{T}_{\mathrm{H}} 17$ cells. $\mathrm{T}$ cells from patients with SLE produce abnormally low levels of IL-2 [39], a cytokine able to prevent the generation of $\mathrm{T}_{\mathrm{H}} 17$ cells and favor that of regulatory $\mathrm{T}$ cells $[40,41]$. Moreover, production of the inflammatory cytokines IL- 6 and IL-21 is enhanced in cells derived from patients with SLE $[42,43]$. Plasmacytoid dendritic cells can induce the conversion of CD4 T cells into $\mathrm{T}_{\mathrm{H}} 17$ cells after stimulation through TLR7 [44]. In patients with SLE, who have circulating immune complexes that contain nucleic acids, this could represent an important mechanism for the amplification of the $\mathrm{T}_{\mathrm{H}} 17$ response (Figure 1).

In summary, IL-17 production is increased in patients with SLE. Elevated IL-17 levels probably contribute to the recruitment and activation of immune cells (e.g., neutrophils and $\mathrm{T}$ cells) to target organs and thus amplify an ensuing immune response. The immune environment in patients with SLE is ideally suited for the generation of IL-17producing T cells. Produced IL-17 probably has broad effects on the immune system that include B cell stimulation [24]. The precise pathways through which IL-17 contributes to SLE pathology will need to be identified in future work.

\section{References}

[1] J. C. Crispín, S.-N. C. Liossis, K. Kis-Toth, et al., "Pathogenesis of human systemic lupus erythematosus: recent advances," Trends in Molecular Medicine, vol. 16, no. 2, pp. 47-57, 2010.

[2] E. Rouvier, M.-F. Luciani, M.-G. Mattei, F. Denizot, and P. Golstein, "CTLA-8, cloned from an activated $T$ cell, bearing AU-rich messenger RNA instability sequences, and homologous to a herpesvirus Saimiri gene," The Journal of Immunology, vol. 150, no. 12, pp. 5445-5456, 1993.

[3] C. T. Weaver and R. D. Hatton, "Interplay between the $\mathrm{T}_{\mathrm{H}} 17$ and $\mathrm{T}_{\text {Reg }}$ cell lineages: a (co-)evolutionary perspective," Nature Reviews Immunology, vol. 9, no. 12, pp. 883-889, 2009.

[4] S. Aggarwal and A. L. Gurney, "IL-17: prototype member of an emerging cytokine family," Journal of Leukocyte Biology, vol. 71, no. 1, pp. 1-8, 2002.

[5] C. T. Weaver, R. D. Hatton, P. R. Mangan, and L. E. Harrington, "IL-17 family cytokines and the expanding diversity of effector T cell lineages," Annual Review of Immunology, vol. 25, pp. 821-852, 2007.

[6] D. Toy, D. Kugler, M. Wolfson, et al., "Cutting edge: interleukin 17 signals through a heteromeric receptor complex," The Journal of Immunology, vol. 177, no. 1, pp. 36-39, 2006.

[7] T. Korn, E. Bettelli, M. Oukka, and V. K. Kuchroo, "IL-17 and Th17 cells," Annual Review of Immunology, vol. 27, pp. 485$517,2009$.

[8] A. Peck and E. D. Mellins, "Precarious balance: Th17 cells in host defense," Infection and Immunity, vol. 78, no. 1, pp. 32$38,2010$.

[9] A. M. Woltman, S. de Haij, J. G. Boonstra, S. J. P. Gobin, M. R. Daha, and C. van Kooten, "Interleukin-17 and CD40-Ligand synergistically enhance cytokine and chemokine production by renal epithelial cells," Journal of the American Society of Nephrology, vol. 11, no. 11, pp. 2044-2055, 2000.

[10] J. Witowski, K. Pawlaczyk, A. Breborowicz, et al., "IL-17 stimulates intraperitoneal neutrophil infiltration through the release of GRO $\alpha$ chemokine from mesothelial cells," The Journal of Immunology, vol. 165, no. 10, pp. 5814-5821, 2000.

[11] M. J. Ruddy, F. Shen, J. B. Smith, A. Sharma, and S. L. Gaffen, "Interleukin-17 regulates expression of the CXC chemokine LIX/CXCL5 in osteoblasts: implications for inflammation and neutrophil recruitment," Journal of Leukocyte Biology, vol. 76, no. 1, pp. 135-144, 2004.

[12] M. Laan, Z.-H. Cui, H. Hoshino, et al., "Neutrophil recruitment by human IL-17 via C-X-C chemokine release in the airways," The Journal of Immunology, vol. 162, no. 4, pp. 23472352, 1999.

[13] C. Albanesi, A. Cavani, and G. Girolomoni, "IL-17 is produced by nickel-specific $\mathrm{T}$ lymphocytes and regulates ICAM-1 expression and chemokine production in human keratinocytes: synergistic or antagonist effects with IFN- $\gamma$ and TNF- $\alpha$," The Journal of Immunology, vol. 162, no. 1, pp. 494502, 1999.

[14] P. Schwarzenberger, W. Huang, P. Ye, et al., "Requirement of endogenous stem cell factor and granulocyte-colonystimulating factor for IL-17-mediated granulopoiesis," The Journal of Immunology, vol. 164, no. 9, pp. 4783-4789, 2000.

[15] X.-Y. Cai, C. P. Gommoll Jr., L. Justice, S. K. Narula, and J. S. Fine, "Regulation of granulocyte colony-stimulating factor gene expression by interleukin-17," Immunology Letters, vol. 62, no. 1, pp. 51-58, 1998.

[16] M. J. Ruddy, G. C. Wong, X. K. Liu, et al., "Functional cooperation between interleukin-17 and tumor necrosis factor$\alpha$ is mediated by CCAAT/enhancer-binding protein family members," Journal of Biological Chemistry, vol. 279, no. 4, pp. 2559-2567, 2004.

[17] P. Miossec, "Interleukin-17 in rheumatoid arthritis: if T cells were to contribute to inflammation and destruction through synergy," Arthritis and Rheumatism, vol. 48, no. 3, pp. 594-601, 2003.

[18] R. L. Van Bezooijen, H. C. M. Farih-Sips, S. E. Papapoulos, and C. W. Lowik, "Interleukin-17: a new bone acting cytokine in vitro," Journal of Bone and Mineral Research, vol. 14, no. 9, pp. 1513-1521, 1999.

[19] D. Q. Shih, S. R. Targan, and D. McGovern, "Recent advances in IBD pathogenesis: genetics and immunobiology," Current Gastroenterology Reports, vol. 10, no. 6, pp. 568-575, 2008.

[20] K. Kurasawa, K. Hirose, H. Sano, et al., "Increased interleukin17 production in patients with systemic sclerosis," Arthritis and Rheumatism, vol. 43, no. 11, pp. 2455-2463, 2000.

[21] J. C. Crispin, M. Oukka, G. Bayliss, et al., "Expanded double negative T cells in patients with systemic lupus erythematosus produce IL-17 and infiltrate the kidneys," The Journal of Immunology, vol. 181, no. 12, pp. 8761-8766, 2008.

[22] C. K. Wong, L. C. W. Lit, L. S. Tam, E. K. M. Li, P. T. Y. Wong, and C. W. K. Lam, "Hyperproduction of IL-23 and IL17 in patients with systemic lupus erythematosus: implications for Th17-mediated inflammation in auto-immunity," Clinical Immunology, vol. 127, no. 3, pp. 385-393, 2008.

[23] C. K. Wong, C. Y. Ho, E. K. Li, and C. W. K. Lam, "Elevation of proinflammatory cytokine (IL-18, IL-17, IL-12) and Th2 cytokine (IL-4) concentrations in patients with systemic lupus erythematosus," Lupus, vol. 9, no. 8, pp. 589-593, 2000.

[24] A. Doreau, A. Belot, J. Bastid, et al., "Interleukin 17 acts in synergy with B cell-activating factor to influence B cell biology and the pathophysiology of systemic lupus erythematosus," Nature Immunology, vol. 10, no. 7, pp. 778-785, 2009.

[25] J. Yang, Y. Chu, X. Yang, et al., "Th17 and natural treg cell population dynamics in systemic lupus erythematosus," Arthritis and Rheumatism, vol. 60, no. 5, pp. 1472-1483, 2009. 
[26] J. C. Crispin and G. C. Tsokos, "Human TCR- $\alpha \beta^{+} \mathrm{CD} 4^{-} \mathrm{CD} 8^{-}$ $\mathrm{T}$ cells can derive from $\mathrm{CD} 8^{+} \mathrm{T}$ cells and display an inflammatory effector phenotype," The Journal of Immunology, vol. 183, no. 7, pp. 4675-4681, 2009.

[27] Y. Wang, S. Ito, Y. Chino, et al., "Laser microdissection-based analysis of cytokine balance in the kidneys of patients with lupus nephritis," Clinical and Experimental Immunology, vol. 159, no. 1, pp. 1-10, 2010.

[28] G. Dong, R. Ye, W. Shi, et al., "IL-17 induces autoantibody overproduction and peripheral blood mononuclear cell overexpression of IL-6 in lupus nephritis patients," Chinese Medical Journal, vol. 116, no. 4, pp. 543-548, 2003.

[29] Z. Zhang, V. C. Kyttaris, and G. C. Tsokos, "The role of IL23/IL-17 axis in lupus nephritis," The Journal of Immunology, vol. 183, no. 5, pp. 3160-3169, 2009.

[30] Y. Wang, S. Ito, Y. Chino, et al., "Use of laser microdissection in the analysis of renal-infiltrating T cells in MRL/lpr mice," Modern Rheumatology, vol. 18, no. 4, pp. 385-393, 2008.

[31] H.-K. Kang, M. Liu, and S. K. Datta, "Low-dose peptide tolerance therapy of lupus generates plasmacytoid dendritic cells that cause expansion of autoantigen-specific regulatory $\mathrm{T}$ cells and contraction of inflammatory Th17 cells," The Journal of Immunology, vol. 178, no. 12, pp. 7849-7858, 2007.

[32] H. Y. Wu, F. J. Quintana, and H. L. Weiner, "Nasal anti-CD3 antibody ameliorates lupus by inducing an IL-10-secreting CD4 ${ }^{+}$," The Journal of Immunology, vol. 181, pp. 6038-6050, 2008.

[33] H.-C. Hsu, T. Zhou, H. Kim, et al., "Production of a novel class of polyreactive pathogenic autoantibodies in BXD2 mice causes glomerulonephritis and arthritis," Arthritis and Rheumatism, vol. 54, no. 1, pp. 343-355, 2006.

[34] H.-C. Hsu, P. A. Yang, J. Wang, et al., "Interleukin 17producing $\mathrm{T}$ helper cells and interleukin 17 orchestrate autoreactive germinal center development in autoimmune BXD2 mice," Nature Immunology, vol. 9, no. 2, pp. 166-175, 2008.

[35] H.-C. Hsu, Y. Wu, P. Yang, et al., "Overexpression of activation-induced cytidine deaminase in B cells is associated with production of highly pathogenic autoantibodies," The Journal of Immunology, vol. 178, no. 8, pp. 5357-5365, 2007.

[36] M. Veldhoen, R. J. Hocking, C. J. Atkins, R. M. Locksley, and B. Stockinger, "TGF $\beta$ in the context of an inflammatory cytokine milieu supports de novo differentiation of IL-17-producing $\mathrm{T}$ cells," Immunity, vol. 24, pp. 179-189, 2006.

[37] L. Yang, D. E. Anderson, C. Baecher-Allan, et al., "IL-21 and TGF- $\beta$ are required for differentiation of human $\mathrm{T}_{\mathrm{H}} 17$ cells," Nature, vol. 454, pp. 350-352, 2008.

[38] P. R. Mangan, L. E. Harrington, D. B. O'Quinn, et al., "Transforming growth factor- $\beta$ induces development of the $\mathrm{T}_{\mathrm{H}} 17$ lineage," Nature, vol. 441, pp. 231-234, 2006.

[39] J. Alcocer-Varela and D. Alarcon-Segovia, "Decreased production of and response to interleukin-2 by cultured lymphocytes from patients with systemic lupus erythematosus," Journal of Clinical Investigation, vol. 69, no. 6, pp. 1388-1392, 1982.

[40] B. Stockinger, "Good for goose, but not for gander: IL-2 interferes with Th17 differentiation," Immunity, vol. 26, no. 3, pp. 278-279, 2007.

[41] E. Bettelli, Y. Carrier, W. Gao, et al., "Reciprocal developmental pathways for the generation of pathogenic effector $\mathrm{T}_{\mathrm{H}} 17$ and regulatory T cells," Nature, vol. 441, no. 7090, pp. 235-238, 2006.

[42] M. Linker-Israeli, R. J. Deans, D. J. Wallace, J. Prehn, T. OzeriChen, and J. R. Klinenberg, "Elevated levels of endogenous IL-6 in systemic lupus erythematosus: a putative role in pathogenesis," The Journal of Immunology, vol. 147, no. 1, pp. 117-123, 1991.

[43] C. K. Wong, P. T. Y. Wong, L. S. Tam, E. K. Li, D. P. Chen, and C. W. K. Lam, "Elevated production of B cell chemokine CXCL13 is correlated with systemic lupus erythematosus disease activity," Journal of Clinical Immunology, vol. 30, no. 1, pp. 45-52, 2010.

[44] C. F. Yu, W. M. Peng, J. Oldenburg, et al., "Human plasmacytoid dendritic cells support Th17 cell effector function in response to TLR7 ligation," The Journal of Immunology, vol. 184, no. 3, pp. 1159-1167, 2010. 


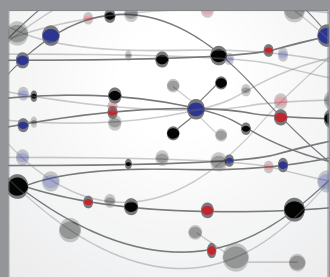

The Scientific World Journal
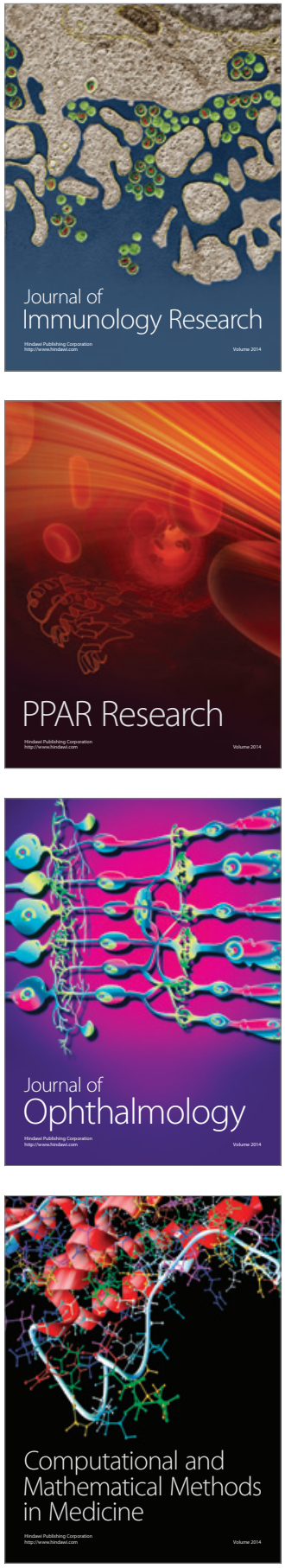

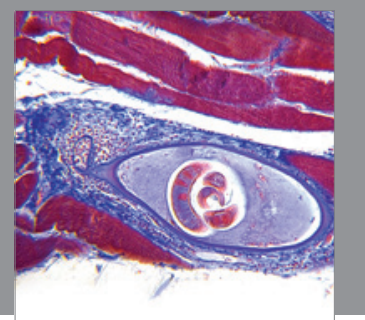

Gastroenterology

Research and Practice
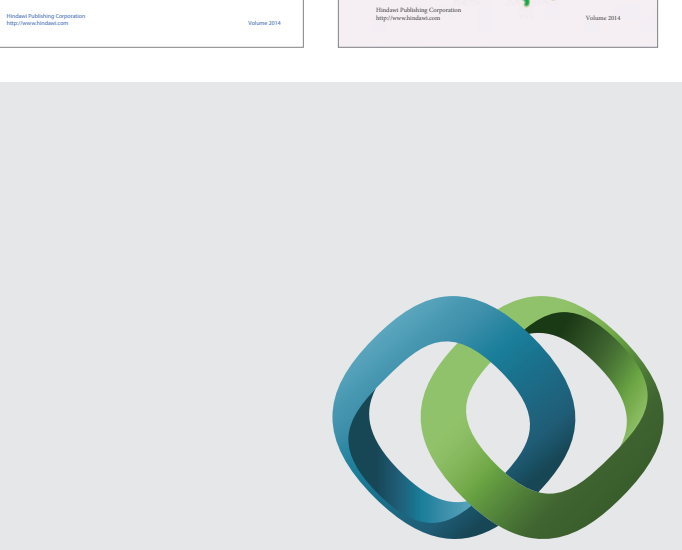

\section{Hindawi}

Submit your manuscripts at

http://www.hindawi.com
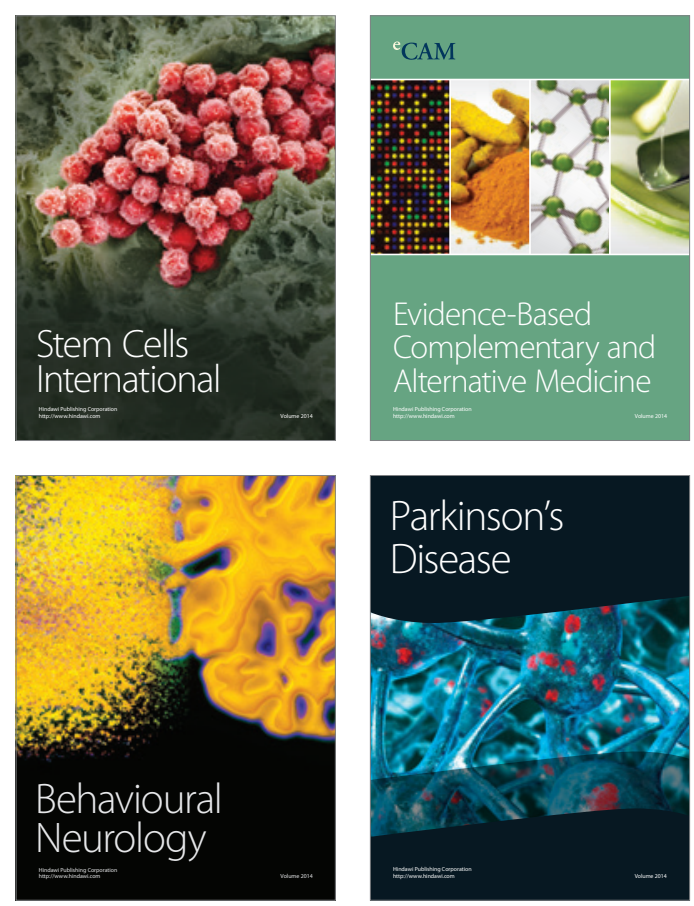

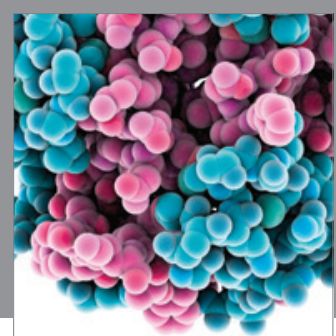

Journal of
Diabetes Research

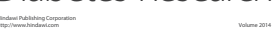

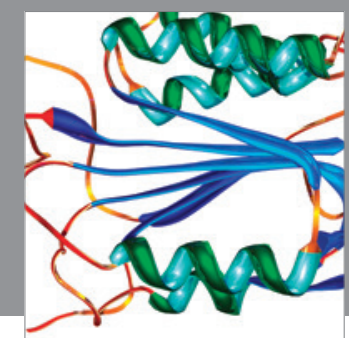

Disease Markers
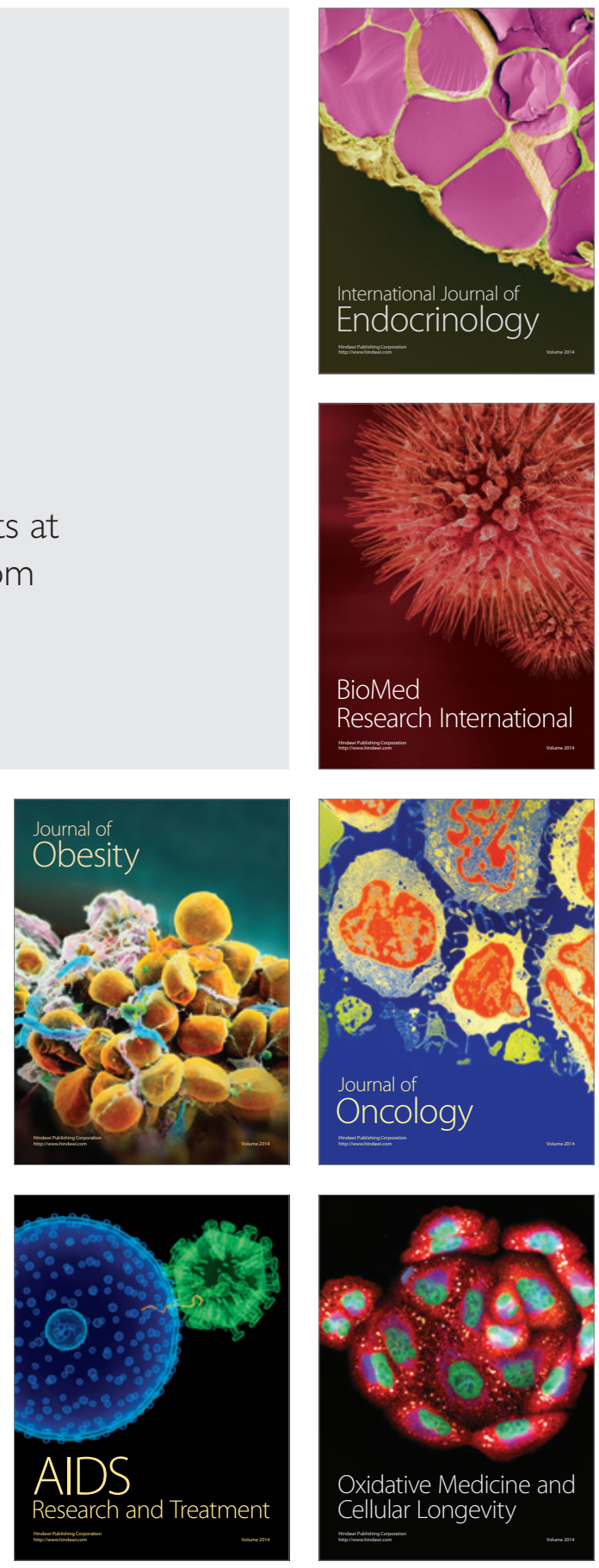